\title{
Individuals with Fear of Blushing Explicitly and Automatically Associate Blushing with Social Costs
}

\author{
Klaske A. Glashouwer • Peter J. de Jong • Corine Dijk • \\ Femke M. Buwalda
}

Published online: 28 July 2011

(C) The Author(s) 2011. This article is published with open access at Springerlink.com

\begin{abstract}
To explain fear of blushing, it has been proposed that individuals with fear of blushing overestimate the social costs of their blushing. Current informationprocessing models emphasize the relevance of differentiating between more automatic and more explicit cognitions, as both types of cognitions may independently influence behavior. The present study tested whether individuals with fear of blushing expect blushing to have more negative social consequences than controls, both on an explicit level and on a more automatic level. Automatic associations between blushing and social costs were assessed in a treatment-seeking sample of individuals with fear of blushing who met DSM-IV criteria for social anxiety disorder $(n=49)$ and a non-anxious control group $(n=27)$ using a single-target Implicit Association Test (stIAT). In addition, participants' explicit expectations about the social costs of their blushing were assessed. Individuals with fear of blushing showed stronger associations between blushing and negative outcomes, as indicated by both stIAT and selfreport. The findings support the view that automatic and explicit associations between blushing and social costs may both help to enhance our understanding of the cognitive processes that underlie fear of blushing.
\end{abstract}

Keywords Fear of blushing · Automatic associations . Single-target implicit association test

\footnotetext{
K. A. Glashouwer $(\bowtie) \cdot$ P. J. de Jong $\cdot$ F. M. Buwalda Department of Clinical Psychology, University of Groningen, Grote Kruisstraat 2/1,

9712 TS Groningen, The Netherlands

e-mail: k.a.glashouwer@rug.nl

C. Dijk

Department of Clinical Psychology, University of Amsterdam, Amsterdam, The Netherlands
}

Blushing is a common physiological response assumed to occur in situations in which people suddenly become conscious of themselves (Crozier 2006). While there is evidence that blushing is functional for interpersonal communication (e.g., Leary et al. 1996; Dijk and de Jong 2009; Dijk et al. 2011), people often experience their blushing as an undesirable response to the extent that they try to prevent or hide it (Shields et al. 1990). For some individuals blushing is so unpleasant that they develop a fear of blushing (e.g., Mulkens et al. 2001). It is increasingly common for individuals with fear of blushing to undergo interventions for their blushing (e.g., surgical procedures; Dijk and de Jong 2006), which underlines the negative consequences of this condition. Consequently, it seems essential to increase insight into the cognitive processes that may underlie fear of blushing.

Recently, it was proposed that the highly negative evaluation of blushing in individuals with fear of blushing may be due to an overestimation of the social costs of blushing. That is, individuals with fear of blushing may fear being seen by others as incompetent, unlikeable, and unreliable (e.g., Bögels and Reith 1999; Dijk et al. 2010; Dijk et al. 2009). In previous studies, we have used vignettes to assess in individuals with fear of blushing their expectations of displaying a blush in several types of situations: after a social transgression, when being the center of attention, during the disclosure of something personal, and in circumstances in which people usually do not blush (de Jong and Peters 2005; de Jong et al. 2006; Dijk and de Jong 2009; Dijk et al. 2010). These studies showed that, compared to individuals with low fear of blushing, individuals with high fear of blushing anticipated heightened social costs of their blushing only in circumstances during which people usually do not blush. In another recent study, individuals were asked about their 
cognitions concerning blushing without providing a specific context. This study also showed that individuals with fear of blushing expected blushing to be associated with higher social costs than individuals with low fear of blushing (Dijk et al. 2010). Together, these findings seem to indicate that fear of blushing is characterized by an overestimation of the social costs of blushing.

Thus far, research into fear of blushing has mostly relied on self-report questionnaires and therefore has been focused on the consciously accessible traces of blushing cognitions. However, dual process models emphasize the need to distinguish between these so-called explicit beliefs and more automatic levels of information-processing. These models assume that behavior is not only guided by cognitions of which people are consciously aware, but also by processes that occur more automatically, and often involuntary, or even completely outside awareness (e.g., Gawronski and Bodenhausen 2006). Current cognitive models of anxiety disorders stress the importance of these automatic processes and assume that threatening stimuli will directly activate fear associations in memory. In turn these associations will automatically elicit fear responses such as feelings of anxiety, anxious thoughts and defensive behaviors (Beck and Clark 1997). Especially in circumstances in which individuals have little opportunity or limited cognitive capacity to reflect on the situation, fear responses occur more spontaneously and are assumed to result from these more automatic associations (Fazio and Towles-Schwen 1999). In support of this, several studies have shown that automatic associations have predictive validity for relatively spontaneous fear responses (e.g. Spalding and Hardin 1999; Egloff and Schmukle 2002; Huijding and de Jong 2006). Likewise, automatic associations may also play an important role in fear of blushing. Thus, for a proper understanding of the processes underlying fear of blushing it may be of critical importance to conduct research testing the relevance of more automatically activated associations between blushing and social costs. This will complement previous research that predominantly focused on the more deliberate cognitions regarding social costs (de Jong and Peters 2005; de Jong et al. 2006; Dijk and de Jong 2009; Dijk et al. 2010).

Therefore, the present study was designed to examine whether individuals with a fear of blushing display stronger automatic associations between blushing and social costs than controls without fear of blushing. To assess the strength of these automatic associations, we used a singletarget Implicit Association Test (stIAT) shown to be sensitive to individual differences (e.g., Huijding and de Jong 2006; Karpinsky and Steinman 2006; Thush and Wiers 2007; Wigboldus et al. 2002). The stIAT is used in the present study as a context-independent measure of automatic blushing associations. Therefore as an explicit equivalent of the automatic blushing associations we also included a self-report measure of social costs that was context-independent (cf. Dijk et al. 2010). Prior studies on the role of anticipated social costs in fear of blushing have predominantly relied on analogue samples. However, there may be quantitative as well as qualitative differences between analogue and clinical samples (Emmelkamp 1982), and so the present study included a clinical sample. This clinical sample consisted of treatment-seeking individuals with social anxiety disorder and fear of blushing as their primary complaint. This was not only important for the external validity of the present study, but also made it possible to see whether previous findings from analogue samples regarding explicit self-reported social costs of blushing could be replicated in a clinical sample.

\section{Method}

Participants and Procedure

The data presented here are part of a larger study on the efficacy of a new psychoeducational intervention for individuals with fear of blushing (Dijk et al. in press). Participants were 52 individuals who applied for treatment because of their fear of blushing and 27 non-fearful controls. Fearful participants applied for treatment after reading articles about a fear of blushing treatment study that appeared in both local and national media. Control participants were all indirect acquaintances of the staff members of the Department of Clinical Psychology of the University of Groningen who were asked via these staff members to serve as control participants in a study on fear of blushing. They were screened with the blushing scale of the Blushing Trembling Sweating Questionnaire (BTSQ, Bögels and Reith 1999). Control participants scoring over 50 on the blushing scale of the BTSQ were considered fearful of blushing and therefore excluded $(n=1)$. Mean BTSQ blushing scores for the control group were lower than those of the fearful group (Table 1). The two groups were similar with respect to gender, age, and educational level.

Individuals with fear of blushing were included when they met the DSM-IV criteria (APA 2000) for social phobia on the Minnesota International Neuropsychiatric InterviewPlus (MINI-Plus, version 5.0.0; Sheehan et al. 1998) and had fear of blushing as the main symptom. The MINI-Plus is a concise structured interview that can be used as a screening instrument for the most important Axis I diagnoses according to the DSM-IV. Five participants with fear of blushing had a comorbid diagnosis: one participant suffered from agoraphobia, one participant from panic disorder, one participant had a current depressive episode, 
Table 1 Means and standard deviations of variables as a function of group

\begin{tabular}{|c|c|c|c|}
\hline \multirow[t]{2}{*}{ Variables } & \multicolumn{2}{|l|}{ Group } & \multirow[t]{2}{*}{$T$-statistics } \\
\hline & $\begin{array}{l}\mathrm{NFC} \\
N=27\end{array}$ & $\begin{array}{l}\mathrm{FB} \\
N=49\end{array}$ & \\
\hline Gender, $\%$ female & 77.8 & 73.5 & 0.41 \\
\hline Age & $34.30(12.68)$ & $39.43(11.35)$ & 1.81 \\
\hline Educational level ${ }^{\text {a }}$ & $2.67(0.92)$ & $2.61(0.93)$ & 0.25 \\
\hline $\begin{array}{l}\text { stIAT blushing, } \\
\text { D-measure }\end{array}$ & $-0.13(0.47)$ & $-0.37(0.42)$ & $2.29 *$ \\
\hline $\begin{array}{l}\text { stIAT blushing, \% error } \\
\text { trials overall }\end{array}$ & $6.62(6.24)$ & $8.28(6.17)$ & 1.12 \\
\hline Pairing blush-positive & $5.65(6.48)$ & $11.77(10.92)$ & $3.07 * *$ \\
\hline Pairing blush-negative & $5.59(6.95)$ & $4.80(4.23)$ & $1.90 \dagger$ \\
\hline Others' evaluations ${ }^{\mathrm{b}}$ & $6.00(1.62)$ & $3.23(1.56)$ & $7.32 * *$ \\
\hline Blushing Questionnaire $^{\mathrm{c}}$ & $9.16(6.97)$ & $73.77(12.59)$ & $24.62 * *$ \\
\hline
\end{tabular}

stIAT single target Implicit Association Test, NFC non-fearful controls, $F B$ individuals with fear of blushing

a educational level in categories of ' 1 ' tot ' 4 ', where ' 1 ' stands for lower education and ' 4 ' for higher education

${ }^{\mathrm{b}}$ 9-item subscale of the Conditional Cognition scale

${ }^{\mathrm{c}}$ 5-item subscale of the Blushing, Trembling, and Sweating Questionnaire

$* * p<0.01$ (2-tailed);

$* p<0.05$ level (2-tailed);

$\dagger p<0.10$ (2-tailed)

one participant was dysthymic with low suicidality as well as agoraphobic and one participant was afraid of needles. The control group was not screened for additional psychopathological symptoms, because having additional psychopathological symptoms was allowed for all participants. Further inclusion criteria for all participants were being 18 years or older and having a good command of the Dutch language. Exclusion criteria for the individuals with fear of blushing were the presence of other DSM-IV Axis I disorders more prominent than fear of blushing and prior or ongoing Cognitive Behavioral Therapy (CBT). The stIAT was administered after the MINI-plus was finished. It was presented as separate from the psychoeducational intervention and participants could choose not to participate but still undergo the intervention. The test session lasted about $45 \mathrm{~min}$ and consisted of the stIAT followed by self-report questionnaires, all administered by a computer. By using a fixed order of administration we tried to minimize the influence of the self-reports on the stIAT (cf. Bosson et al. 2000).

\section{Measurements}

Fear of Blushing Severity of fear of blushing was measured with the 'blushing' subscale of the BTSQ. On this 5-item subscale, people answer on a Visual Analogue Scale questions with respect to their fear of blushing (e.g. "How afraid are you that you will be blushing?" Not at all afraid - Very afraid). Mean subscale scores (range 0-100) were calculated over the five items.

Single Target Implicit Association Test (stIAT) To assess the strength of automatic blushing associations we used a single-target Implicit Association Test (stIAT) originally designed by Wigboldus et al. (2002). The stIAT is a computerized reaction time task that measures to what extent a single target category is associated with two attribute categories. Following prior designs (Huijding and de Jong 2006; Karpinsky and Steinman 2006; Thush and Wiers 2007; Wigboldus et al. 2002), a blushing stIAT was constructed with the target category blushing and the attribute categories positive outcome and negative outcome. Positive and negative social judgments of blushing typically contain attributes from the domains of competence, sociability, likeability, and reliability (e.g., Dijk and de Jong 2009). Consequently, attributes from these domains were used as stimuli in the present stIAT. Each category consisted of five stimulus words. These were color, tomato, blush, glow, and red for blushing, charming, fun, social, sincere, and kind for positive outcome, and shame, fail, flop, disappointing and disapproval for negative outcome (translated from Dutch). Stimulus words from all three categories appeared in randomized order in the middle of a computer screen and participants were instructed to sort them with a left or right response key. The category names stayed visible in the upper left and right-hand corners of the screen during the whole task. The premise here is that the sorting becomes easier when a target and attribute that share the same response key are strongly associated than when they are weakly associated (e.g., for a person with fear of blushing it is probably easier to categorize words of blushing and negative outcome with the same button than blushing and positive outcome). The task consisted of two critical test blocks that were preceded by practice blocks (Table 2). In one test block blushing and positive outcome were mapped on one response key, and negative outcome on the other. In

Table 2 Arrangement of stIAT blushing

\begin{tabular}{llll}
\hline Block & Left & Right & Practice/test \\
\hline 1 & Negative & Blushing + Positive & Practice \\
\# Stimuli & 5 & $5+5$ & \\
2 & Negative & Blushing + Positive & Test \\
\# Stimuli & 40 & $20+20$ & \\
3 & Blushing + Negative & Positive & Practice \\
\# Stimuli & $5+5$ & 5 & \\
4 & Blushing + Negative & Positive & Test \\
\# Stimuli & $20+20$ & 40 & \\
\hline
\end{tabular}


the other test block blushing and negative outcome were mapped on one key and positive outcome on the other. To prevent response bias, correct responses of the test blocks were divided equally over the two response keys (cf. Bluemke et al. 2009). Before the start of a new sorting task, written instructions were presented on the screen. After a correct response, the next stimulus was presented with a $500 \mathrm{~ms}$ delay. After an incorrect response, the Dutch word FOUT! (wrong) appeared shortly above the stimulus, and the stimulus remained on the screen until the correct response was given. The order of test blocks was counterbalanced between participants.

Explicit Blushing Cognitions Participants' explicit expectations about the social costs of their blushing were measured with the 'others' evaluations' subscale of the Conditional Cognition scale (see Dijk et al. 2010). This 9-item subscale contains questions aiming at participants' cognitions about others' evaluations when blushing ("when I blush, others will think I am... competent, insecure, etc."). The questions could be answered on a scale from 0 (applies totally to me) to 10 (does not apply to me at all). Mean subscale scores were calculated over the nine items; higher scores indicate more positive expectations of blushing.

\section{Data Analyses}

stIAT effects were computed according to the now widely used algorithm proposed by Greenwald et al. (2003) that can also be used for analyzing the stIAT (cf. Karpinsky and Steinman 2006; Thush and Wiers 2007). In this paper, we report the so-called $\mathrm{D}_{4}$-measure. ${ }^{1}$ Following the algorithm, all reaction times above $10,000 \mathrm{~ms}$ were discarded. Error trials were replaced with the mean reaction times of the correct responses in the block in which the error occurred, plus a penalty of $600 \mathrm{~ms}$. The stIAT effect was calculated by subtracting the mean reaction times of Block 2 (4) from Block 4 (2). This effect was divided by the pooled standard deviation based on all responses in Blocks 2 and 4. Practice trials were discarded from the analyses, because we considered these trials to be truly practice: each stimulus was presented once to the participant and likewise the responses were not divided equally over the response keys. Negative stIAT effects indicate faster responses when blushing shared the response key with negative outcome. The bivariate Pearson's correlation coefficient was used to calculate the strength of the association between stIAT and

\footnotetext{
${ }^{1}$ Because the present IAT design did not record the second correct response after a mistake, no built-in error penalty could be used. However, we repeated the analyses with the other available variants of the D-measure $\left(D_{3}, D_{5}, D_{6}\right)$, but did not find any differences with respect to the outcomes.
}

explicit cognitions. T-tests were used to calculate the simple group effects in Table 1 and in Fig. 1 and univariate ANOVAs were used to examine group differences on stIAT blushing and explicit cognitions. The tests were conducted with $\alpha=0.05$.

\section{Results}

\section{Descriptives}

Missing Values Due to technical problems, stIAT data for two participants were missing. Furthermore, one participant appeared fully inexperienced with the use of computers and took over $20 \mathrm{~min}$ to complete the stIAT. Consequently, the data of these three participants were excluded from all analyses. Therefore, the group with fear of blushing (FB) included 49 participants and the non-fearful control group (NFC) included 27 participants. Group mean scores on the stIAT and other variables are reported in Table 1. The splithalf reliability of the present stIAT was excellent, with a Spearman-Brown corrected correlation between test-halves of $0.92\left(\mathrm{D}_{4}\right.$-measure based on odd and even trials). Furthermore, Cronbach's Alpha was calculated over the nine items of the 'others' evaluations' subscale of the Conditional Cognition scale and over the five items of the BTSQ 'blushing' subscale. Both subscales showed good internal consistency (others' evaluations: $\alpha=0.84$; blushing: $\alpha=0.96$ ).

Do Individuals with a Fear of Blushing Differ in their Blushing Associations from Non-fearful Individuals?

A 2 Group $(\mathrm{FB}, \mathrm{NFC}) \times 2$ Order (blushing-positive first, blushing-negative first) ANOVA on automatic blushing associations showed a significant main effect for Group $\left(F(1,72)=5.18, p<0.05\right.$, partial $\left.\eta^{2}=0.07\right)$. As expected, the fearful group showed significantly stronger automatic negative blushing associations (i.e., a faster response when 'blushing' and 'negative outcome' shared the same response key) than the control group (see Fig. 1). The main effect of Order, and the interaction between Order and Group were non-significant ( $p$ s $>0.1$ ).

A two Group (FB, NFC) ANOVA on explicit blushing cognitions showed a significant main effect for Group $\left(F(1,74)=53.64, p<0.01\right.$, partial $\left.\eta^{2}=0.42\right)$ indicating that individuals with fear of blushing had more negative explicit expectations about the social costs of their blushing than the control group. The stIAT scores and explicit cognitions were shown to be largely unrelated ( $r=0.17$, n.s.). This was also evident when 
Fig. 1 Mean RTs of the trials per pairing of the st-IAT blushing: individuals with fear of blushing vs. non-fearful controls

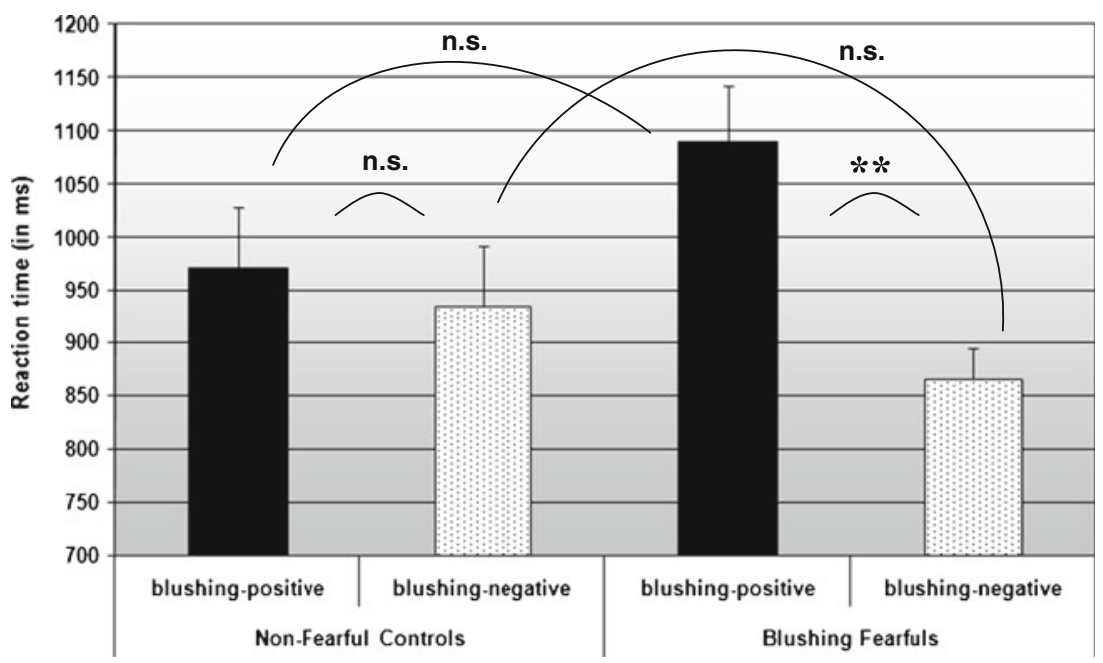

Note . RT $=$ reaction time; stIAT $=$ single target Implicit Association Test; $\mathrm{n} . \mathrm{s} .=$ non significant; $* * p<.01$ (2-tailed). correlations were computed for each group separately (fearfuls: $r=-0.03$, n.s.; controls: $r=0.06$, n.s.).

\section{Discussion}

The present study was designed as a first step in getting more insight into the role of automatic associations between blushing and social costs in fear of blushing in a treatmentseeking sample of individuals with fear of blushing. In line with our predictions, the results showed that the fearful group was characterized by stronger automatic associations between blushing and negative social outcomes (and/or weaker automatic associations between blushing and positive outcomes) than the control group. In addition, individuals with fear of blushing had more negative explicit expectations about the social costs of their blushing than the non-fearful control group. Interestingly, explicit cognitions and automatic associations were shown to be largely unrelated, attesting to the relevance of measuring both automatic and explicit blushing associations for fear of blushing.

In an attempt to explain the highly negative evaluation of blushing in individuals with fear of blushing, it has been proposed that fearful individuals overestimate the social costs of their blushing (Dijk et al. 2009). Furthermore, it has been argued that in addition to explicit beliefs, more automatic dysfunctional associations may be critically involved in fears, such as fear of blushing (e.g., Ouimet et al. 2009). In line with the latter, the present study provided evidence that treatment-seeking individuals with fear of blushing show stronger automatic associations between blushing and social costs than non-fearful controls. In addition, the present findings regarding the explicit index of the anticipated social costs of displaying a blush replicated earlier findings from analogue samples (Dijk et al. 2010). Thus, the present results indicate that individuals with fear of blushing are characterized both by explicit negative expectations about the social costs of their blushing and by more automatic associations between blushing and social costs.

While the pattern of results was in the same direction for automatic as well as explicit blushing associations, we did not find a significant correlation between both types of associations. This fits well within recent informationprocessing models concerning fear that consider explicit and automatic associations as distinct cognitive processes that influence different kinds of behaviors (e.g., Gawronski and Bodenhausen 2006; Ouimet et al. 2009). In individuals with fear of blushing, automatic associations between blushing and social costs might trigger automatically initiated fear responses such as fearful thoughts and behavioral responses (cf. Strack and Deutch 2004). Even when individuals with a fear of blushing have sufficient time and cognitive resources, they will probably not correct these initial dysfunctional associations on a more explicit level, because their explicit beliefs about blushing are similarly negative and dysfunctional. This way automatic and explicit cognitions about blushing may both act to sustain or even enhance the preoccupation with blushing in individuals with fear of blushing (cf. Gawronski and Bodenhausen 2006). Thus, automatic and explicit blushing associations do not seem to be simply redundant. This signifies the importance of measuring both types of cognitions in order to obtain a more comprehensive understanding of the processes that may underlie fear of blushing.

To further examine the causal influence of automatic blushing associations, it will be important to test whether 
the experimental manipulation of these automatic associations leads to changes in fear of blushing (cf. Clerkin and Teachman 2010). Furthermore, the differential predictive validity of automatic versus explicit blushing associations should be tested for actual fearful behaviour in social contexts that might elicit a blushing response (cf. Huijding and de Jong 2006). If dysfunctional automatic associations do indeed play a causal role in the generation and/or maintenance of anxiety symptoms, then both explicit and automatic levels of information processing should be addressed in therapy. Following this, it seems important to investigate whether dysfunctional automatic associations decrease or even disappear under the influence of conventional CBT strategies. On the one hand, it seems possible that $\mathrm{CBT}$ might change automatic processes, for example via explicit attitude change (cf. Gawronski and Bodenhausen 2006) or via behavioral experiments or repeated exposure-in-vivo. On the other hand, it could be that residual dysfunctional automatic associations after CBT are involved in the recurrence of symptoms (cf. Glashouwer et al. in press). In the latter case, existing treatments should be adjusted or extended in a way that dysfunctional cognitions are targeted on both explicit and more automatic levels of information processing.

While the present findings suggest that automatic and explicit associations seem to be distinct cognitive processes, the observed group differences for explicit associations were found to be much larger than for automatic blushing associations. However, it cannot be ruled out that the difference in effect sizes is largely attributable to the methodological approach used. Since fear of blushing and explicit blushing associations were both measured via selfreport measures, considerable method variance could be shared between explicit blushing associations and fear of blushing that is not shared with the automatic associations, making it a much more stringent test for the automatic associations. Secondly, it should be acknowledged that the categories used in the stIAT were not explicitly labeled in terms of social costs but more generally as negative vs. positive outcomes. Future research will have to determine whether more specific automatic cost associations are indeed important in fear of blushing, or whether individuals with fear of blushing are characterized by negative automatic associations with blushing in general. Thirdly, the control group in the present design was not assessed for clinical status. Possibly the degree of psychopathological symptoms was low in the present control group, and, therefore, it cannot be ruled out that other clinical groups besides individuals with fear of blushing might also show negative associations with blushing. Lastly, it would be interesting to compare social anxiety patients with and without a fear of blushing to see whether negative blushing associations are specific for individuals with a fear of blushing or a more general characteristic of social phobia. This comparison could also rule out the possibility that socially anxious individuals have a general tendency to judge situations more negatively, irrespective of blushing per se.

To conclude, the present study not only showed that individuals with fear of blushing explicitly indicate that blushing is associated with negative outcomes, it also revealed that at a more automatic level blushing elicits negative automatic associations in this group. Both types of processes appear to be separate constructs that may help to increase our understanding of fear of blushing. These results imply that it might be valuable to include assessments of automatic associations in addition to the more traditional self-report questionnaires, for example as pre and post measures in the evaluation of treatment (e.g., Huijding and de Jong 2009; Teachman et al. 2008). When conventional treatments do not sufficiently alter dysfunctional automatic associations, it might also be relevant to design new ingredients of CBT that more directly target these automatic associations. As a case in point, it has recently been shown that a computerized association task was effective in reducing social anxiety via modifying participants' dysfunctional automatic associations (Clerkin and Teachman 2010). Together, these findings may help to further increase our understanding of the cognitive processes that underlie fear of blushing.

Acknowledgements We thank Marije aan het Rot, $\mathrm{PhD}$, for checking our manuscript on grammar and spelling, and PSYopleidingen Noord Oost for financial support of the first author.

\section{Declaration of interest None.}

Open Access This article is distributed under the terms of the Creative Commons Attribution Noncommercial License which permits any noncommercial use, distribution, and reproduction in any medium, provided the original author(s) and source are credited.

\section{References}

American Psychiatric Association. (2000). Diagnostic and statistical manual of mental disorders (4th ed., Text Revision). Washington, DC: Author.

Beck, A. T., \& Clark, D. A. (1997). An information processing model of anxiety: Automatic and strategic processes. Behaviour Research and Therapy, 35, 49-58.

Bluemke, M., Fiedler, K., \& Richter, M. M. (2009). Method effects in Single-Category IATs: asymmetric stimulus base rates and speed gains. Oral presentation presented on the international small group meeting "The transformation of reaction time based measurement approaches: single-category measures", Heidelberg, Germany.

Bögels, S. M., \& Reith, W. (1999). Validity of two questionnaires to assess social fears: The Dutch social phobia and anxiety 
inventory and the blushing, trembling and sweating questionnaire. Journal of Psychopathology and Behavioral Assessment, $21,51-66$

Bosson, J. K., Swann, W. B., Jr., \& Pennebaker, J. W. (2000). Stalking the perfect measure of implicit self-esteem: The blind men and the elephant revisited? Journal of Personality and Social Psychology, 79, 631-643.

Clerkin, E. M., \& Teachman, B. A. (2010). Training implicit social anxiety associations: An experimental intervention. Journal of Anxiety Disorders, 24, 300-308.

Crozier, W. R. (2006). Blushing and the social emotions: The self unmasked. New York: Palgrave MacMillan.

de Jong, P. J., \& Peters, M. L. (2005). Do blushing phobics overestimate the undesirable communicative effects of their blushing? Behaviour Research and Therapy, 43, 747-758.

de Jong, P. J., Peters, M. L., Dijk, C., Nieuwenhuis, E., Kempe, H., \& Oelerink, J. (2006). Fear of blushing: The role of the expected influence of displaying a blush on others' judgments. Cognitive Therapy and Research, 30, 623-634.

Dijk, C., \& de Jong, P. J. (2006). Surgical treatment for blushing. The Lancet, 367, 2059

Dijk, C., \& de Jong, P. J. (2009). Fear of blushing: No overestimation of negative anticipated interpersonal effects, but a high subjective probability of blushing. Cognitive Therapy and Research, 33, $59-74$.

Dijk, C., Voncken, M. J., \& de Jong, P. J. (2009). I blush, therefore I will be judged negatively: Influence of false blush feedback on anticipated others' judgments and facial coloration in high and low blushing-fearfuls. Behaviour Research and Therapy, 47, 541-547.

Dijk, C., de Jong, P. J., Müller, E., \& Boersma, W. (2010). Blushingfearful individuals' judgmental biases and conditional cognitions: An internet inquiry. Journal of Psychopathology and Behavioral Assessment, 32, 264-270.

Dijk, C., Koenig, B., Ketelaar, T., \& de Jong, P. J. (2011). Saved by the blush: Being trusted despite defecting. Emotion, 11, 313-319.

Dijk, C., Buwalda, F. M., \& de Jong, P. J. (in press). Dealing with fear of blushing: a psychoeducational group intervention for fear of blushing. Clinical Psychology \& Psychotherapy.

Egloff, B., \& Schmukle, S. C. (2002). Predictive validity of an implicit association test for assessing anxiety. Journal of Personality and Social Psychology, 83, 1441-1455.

Emmelkamp, P. (1982). Phobic and obsessive compulsive disorders: Theory, research and practice. New York: Plenum.

Fazio, R. H., \& Towles-Schwen, T. (1999). In Y. Trope (Ed.), The MODE model of attitude-behavior processes. New York: Guilford.

Glashouwer, K. A., de Jong, P. J., \& Penninx, B. W. J. H. (in press). Predictive validity of automatic self-associations for the onset of anxiety disorders. Journal of Abnormal Psychology.

Gawronski, B., \& Bodenhausen, G. V. (2006). Associative and propositional processes in evaluation: An integrative review of implicit and explicit attitude change. Psychological Bulletin, 132, 692-731.

Greenwald, A. G., Nosek, B. A., \& Banaji, M. R. (2003). Understanding and using the implicit association test: I. An improved scoring algorithm. Journal of Personality and Social Psychology, 85, 197-216.

Huijding, J., \& de Jong, P. J. (2006). Automatic associations with the sensory aspects of smoking: Positive in habitual smokers but negative in non-smokers. Addictive Behaviors, 31, 182-186.

Huijding, J., \& de Jong, P. J. (2009). Implicit and explicit attitudes toward spiders: Sensitivity to treatment and predictive value for generalization of treatment effects. Cognitive Therapy and Research, 33, 211-220.

Karpinsky, A., \& Steinman, R. B. (2006). The single category implicit association test as a measure of implicit social cognition. Journal of Personality and Social Psychology, 91, 16-32.

Leary, M. R., Landel, J. L., \& Patton, K. M. (1996). The motivated expression of embarassment following a self-presentational predicament. Journal of Personality, 64, 619-636.

Mulkens, S., Bögels, S. M., de Jong, P. J., \& Louwers, J. (2001). Fear of blushing: Effects of task concentration training versus exposure in vivo on fear and physiology. Journal of Anxiety Disorders, 15, 413-432.

Ouimet, A. J., Gawronski, B., \& Dozois, D. J. A. (2009). Cognitive vulnerability to anxiety: A review and an integrative model. Clinical Psychology Review, 29, 459-470.

Sheehan, D. V., Lecrubier, Y., Sheehan, K. H., Amorim, P., Janavs, J., Weiller, E., et al. (1998). The Mini-International Neuropsychiatric Interview (MINI): The development and validation of a structured diagnostic psychiatric interview for DSM-IV and ICD- 10. The Journal of Clinical Psychiatry, 59, 22-33.

Shields, S. A., Mallory, M. E., \& Simon, A. (1990). The experience and symptoms of blushing as a function of age and reported frequency of blushing. Journal of Nonverbal Behavior, 14, 171-187.

Spalding, L. R., \& Hardin, C. D. (1999). Unconscious unease and self-handicapping: Behavioral consequences of individual differences in implicit and explicit self-esteem. Psychological Science, 10, 535-539.

Strack, F., \& Deutch, R. (2004). Reflective and impulsive determinants of social behavior. Personality and Social Psychology Review, 8, 220-247.

Teachman, B. A., Marker, J. D., \& Smith-Janik, S. B. (2008). Automatic associations and panic disorder: Trajectories of change over the course of treatment. Journal of Consulting and Clinical Psychology, 76, 988-1002.

Thush, C., \& Wiers, R. W. (2007). Explicit and implicit alcohol-related cognitions and the prediction of future drinking in adolescents. Addictive Behaviors, 32, 1367-1383.

Wigboldus, D. H. J., Holland, R. W., van Knippenberg, A., den Hartog, G., \& Belles, S. (2002). Het verschil tussen relatieve en absolute vergelijking bij het testen van impliciete associaties. In D. A. Stapel, M. Hagedoorn, \& E. van Dijk (Eds.), Jaarboek sociale psychologie 2001 (pp. 337-346). Delft: Eburon. 